\title{
Failing to plan and planning to fail. Can we predict the future growth of demand on UK Eye Care Services?
}

\author{
John Cameron Buchan $\mathbb{1 0}^{1} \cdot$ Paul Norman $\mathbb{1}^{2} \cdot$ Darren Shickle $^{3} \cdot$ Andrew Cassels-Brown $^{4} \cdot$ Carrie MacEwen $^{5}$
}

Received: 12 July 2017 / Revised: 6 February 2019 / Accepted: 13 February 2019 / Published online: 27 February 2019

(c) The Royal College of Ophthalmologists 2019

\section{Introduction}

The major ophthalmic diseases of public health concern in the UK are cataract, glaucoma, diabetic retinopathy (DR) and age-related macular degeneration (AMD) [1].

Older age is a major risk factor for each of these conditions, and expansion of treatment options has increased the resource allocation necessary per case. Hence with the number of UK residents aged over 75 set to rise from 4.9 million (2010) to 8.9 million (2035), whilst the ratio of working-age to retirement-age populations drops from 3.16 (2010) to 2.87 (2035) [2], there is a pressing national need for proactive service provision planning to avoid a serious and progressive under-provision which cannot be ethically dealt with by continued recruitment of medical staff from nations with greater human resource problems than the UK $[3,4]$.

Planning expansion of services cannot occur without estimation of future demands. We attempted epidemiological modelling, therefore, to quantify the proportional disease burden growth between 2015 and 2035 in so far as that growth is driven by prevalence. In doing so, however, the constraints were as apparent as the possibilities.

John Cameron Buchan

john.buchan@1shtm.ac.uk

1 International Centre for Eye Health, London School of Hygiene and Tropical Medicine, Keppel Street, London WC1E 7HT, UK

2 School of Geography, University of Leeds, Leeds, UK

3 Leeds Institute of Health Sciences, University of Leeds, Leeds, UK

4 Consultant Ophthalmologist, NHS Highland and Orkney Health Board, Leeds, UK

5 Department of Ophthalmology, Ninewells Hospital, University of Dundee, Dundee, UK

\section{Epidemiological modelling-more caveat than confidence?}

Projections of the UK population growth by Office for National Statistics (ONS) are stratified by age and gender. However, with significant variation in disease prevalence between different ethnicities [5, 6] and major UK ethnographic changes expected [7], modelling must incorporate ethnicity. 'ETHPOP' population projections for 12 ethnic groups by age and gender, constrained to ONS projections to 2051, have been produced using a cohort-component model [8, 9]. For example, ETHPOP predicts Asian/British Asian population aged $>80$ to quadruple from $\sim 60,000$ in 2015 to 231,000 in 2035.

Difficulties then arise, starting with the absence of contemporary UK population-based survey data to provide prevalence estimates. Increasingly historic survey data from geographically and genetically disparate contexts were, of necessity, therefore utilised. Furthermore, modelling should take into account age-specific incidence and the effects of becoming a 'case' on life expectancy. Lack of data to permit quantification of the current impact of diagnosis on life expectancy prevents serious consideration of such an approach.

Other known risk factors such as smoking, hypertension, socio-economic status and obesity are not static within the UK population-but modelling to include the expected changes in these factors and their interactions with disease burden is fraught with difficulties; changes in efficacy of treatment modalities for diseases or their risk factors is impossible to predict.

The undeniable size of these obstacles to the generation of academically robust projections of disease burden, does not diminish the equally undeniable need for long-term service delivery planning-which cannot occur in the absence of some attempt to quantify the future needs.

With this in mind, we searched for the most relevant survey data and applied them to the ETHPOP population projections via the National Eye Health Epidemiological 
Model (NEHEM) which facilitates application of disease prevalence to populations (www.eyehealthmodel.org).

\section{Glaucoma}

Published UK Asian population studies [10] cannot be considered widely representative of UK Asian/British Asian populations, so meta-analysis of large studies from both India and Bangladesh was selected [6]. No relevant UK Black population data are available, so meta-analysis was again used with the largest contributing studies utilising West Indies [11], USA [12] and African data [13]. The largest White UK population data were felt to be too old, coming from a survey undertaken in 1995/1996 [14], so large American, European and Australian surveys were accessed [6]. Using these data, a 49\% rise in glaucoma cases from 2015 to 2035 is predicted.

\section{AMD}

Prevalence data for AMD could be taken from UK sources [15]; however, case definition limitations and restriction to age $>75$ made multicentre EUREYE data appear most representative [16]. The lower prevalence of blinding AMD seen in Black populations was accommodated by application of data from the American Eye Diseases Prevalence Research Group [17]. Using these data, a $64 \%$ rise in nAMD cases from 2015 to 2035 is predicted.

\section{Cataract}

Absence of internationally agreed case definition, to which prevalence estimates are extremely sensitive, makes estimation of case numbers of limited value. Proportional increase in those numbers, however, is potentially very useful. Estimates from two surveys were taken [18, 19], and using these data, a $52 \%$ rise in cataract cases is expected from 2015 to 2035 .

\section{Diabetic retinopathy}

The global diabetic population by 2030 has been variously predicted to rise by three separate academic groups to; 366 million [20], 439 million [21] and 552 million [22]. Similarly, two 1997 estimates of growth rate of UK diabetic population were $4.1 \%$ annually [23] and $1.0 \%$ annually [24].

The general scarcity and need for data and future projections to inform ophthalmic public health planning for DR are acknowledged [25]. Despite this need, we concluded that the data did not exist to permit us to attempt this, as the variation in existing projections demonstrates.
Table 1 Estimated and projected numbers of cases of Glaucoma, Cataract and nAMD in the UK 2015-2035

\begin{tabular}{lllllll}
\hline & $\begin{array}{l}\text { Glaucoma cases } \\
\text { \% increase cf } \\
2015)\end{array}$ & $\begin{array}{l}\text { Cataract cases (\% } \\
\text { increase cf 2015) }\end{array}$ & $\begin{array}{l}\text { nAMD cases (\% } \\
\text { increase cf } \\
2015)\end{array}$ \\
\hline 2015 & 659,000 & - & $1,450,000$ & - & 411,000 & - \\
2025 & 807,000 & $23 \%$ & $1,790,000$ & $23 \%$ & 521,000 & $27 \%$ \\
2035 & 983,000 & $49 \%$ & $2,210,000$ & $52 \%$ & 672,000 & $64 \%$ \\
\hline
\end{tabular}

However, if the best indicator of future behaviour is past behaviour, then we should note that UK diabetes prevalence increased from $2.8 \%$ (1996) to $4.3 \%$ (2005), > 50\% rise in 10 years, hence it would seem prudent to anticipate a substantial increase in demand from DR [26]. The scale of this may be similar to the predicted $86 \%$ rise in the diabetic population projected for the USA (2009-2034) [27] or for Germany of a $64 \%$ rise in diagnosed type 2 diabetics [28].

\section{Of what value are these estimates?}

If a large, unquantified and changing proportion of glaucoma is undiagnosed, and visual thresholds for cataract surgery alter surgical numbers far more than prevalence, then it would be reasonable to assert that predicting numbers of 'cases' in a population has little to offer to service planning and that the case numbers in Table 1 can be discounted. However, there must be a substantial proportion of demand that is driven by prevalence, and in so far as the conversion rate between prevalence and demand remains relatively stable, epidemiological modelling gives the best chance of estimating by what proportion demand will rise.

The historic lack of prospective planning for rising demand has allowed a capacity shortfall with welldocumented national-level evidence of harm to patients $[29,30]$. Short-term financial targets make it unattractive for managers to configure services with any excess capacity to accommodate expected growth, hence utilisation of inefficient short-term fixes such as waiting list initiatives, until the system decompensates with serious untoward incidents at which point investment to increase routine capacity becomes unavoidable. This situation must change.

Better source data for planning would require a UK national population-based survey, but until this becomes available, these estimates of proportional increase in case numbers offer some guidance on the size of the growth in service delivery that UK eye care services will be expected to deliver over the next 20 years-and as such should be useful to those taking the long view nationally or locally on resource allocation and workforce planning. Amongst the uncertainties, one thing can be said for sure: if we fail to plan for growth, we are consciously planning to fail our patients in the years to come. 


\section{Compliance with ethical standards}

Conflict of interest The authors declare that they have no conflict of interest.

Publisher's note: Springer Nature remains neutral with regard to jurisdictional claims in published maps and institutional affiliations.

\section{References}

1. Bunce C, Wormald R. Causes of blind certifications in England and Wales: April 1999-March 2000. Eye. 2008;22:905-11.

2. Rutherford T. Population ageing: statistics; wwwparliamentuk/ briefing-papers/sn03228pdf, 2012; SN/SG/3228.

3. Bastawrous A, Hennig BD. The global inverse care law: a distorted map of blindness. Br J Ophthalmol. 2012;96:1357-8.

4. Buchan JC, Amoaku W, Barnes B, Cassels-Brown A, Chang BY, Harcourt J, et al. How to defuse a demographic time bomb: the way forward? Eye. 2017;31:1519-22.

5. Wong WL, Su X, Li X, Cheung CM, Klein R, Cheng CY, et al. Global prevalence of age-related macular degeneration and disease burden projection for 2020 and 2040: a systematic review and meta-analysis. Lancet Glob Health. 2014;2:e106-16.

6. Rudnicka AR, Mt-Isa S, Owen CG, Cook DG, Ashby D. Variations in primary open-angle glaucoma prevalence by age, gender, and race: a Bayesian meta-analysis. Invest Ophthalmol \& Vis Sci. 2006;47:4254-61.

7. Coleman D. Projections of the Ethnic Minority populations of the United Kingdom 2006-2056. Popul Dev Rev. 2010;36:441-86.

8. Rees P, Wohland P, Norman P, Boden P. Ethnic population projections for the UK, 2001-2051. J Popul Res. 2012;29:45-89.

9. Rees PH, Wohland P, Norman P, Lomax N, Clark SD. Population projections by ethnicity: Challenges and a Solution for the United Kingdom. In: Swanson, DA, (ed.) The Frontiers of Applied Demography. Springer International Publishing, (New York City, USA) ISBN 978-3-319-43327-1. 2017. p. 383-408.

10. Rauf A, Malik R, Bunce C, Wormald R. The British Asian community eye study: outline of results on the prevalence of eye disease in British Asians with origins from the Indian subcontinent. Indian J Ophthalmol. 2013;61:53-8.

11. Leske MC, Connell AM, Schachat AP, Hyman L. The Barbados Eye Study. Prevalence of open angle glaucoma. Arch Ophthalmol (Chic, Ill: 1960). 1994;112:821-9.

12. Tielsch JM, Sommer A, Katz J, Royall RM, Quigley HA, Javitt J. Racial variations in the prevalence of primary open-angle glaucoma. The Baltimore Eye Survey. JAMA. 1991;266:369-74.

13. Ntim-Amponsah CT, Amoaku WM, Ofosu-Amaah S, Ewusi RK, Idirisuriya-Khair R, Nyatepe-Coo E, et al. Prevalence of glaucoma in an African population. Eye. 2004;18:491-7.

14. Reidy A, Minassian DC, Vafidis G, Joseph J, Farrow S, Wu J, et al. Prevalence of serious eye disease and visual impairment in a north London population: population based, cross sectional study. BMJ (Clin Res Ed). 1998;316:1643-6.
15. Evans JR, Fletcher AE, Wormald RP. Age-related macular degeneration causing visual impairment in people 75 years or older in Britain: an add-on study to the Medical Research Council Trial of Assessment and Management of Older People in the Community. Ophthalmology. 2004;111:513-7.

16. Augood CA, Vingerling JR, de Jong PT, Chakravarthy U, Seland J, Soubrane G, et al. Prevalence of age-related maculopathy in older Europeans: the European Eye Study (EUREYE). Arch Ophthalmol (Chic, Ill: 1960). 2006;124:529-35.

17. Friedman DS, Wolfs RC, O'Colmain BJ, Klein BE, Taylor HR, West $\mathrm{S}$, et al. Prevalence of open-angle glaucoma among adults in the United States. Arch Ophthalmol (Chic, Ill: 1960). 2004;122:532-8.

18. Frost A, Hopper C, Frankel S, Peters TJ, Durant J, Sparrow J. The population requirement for cataract extraction: a cross-sectional study. Eye. 2001;15(Pt 6):745-52.

19. McCarty CA, Mukesh BN, Fu CL, Taylor HR. The epidemiology of cataract in Australia. Am J Ophthalmol. 1999;128:446-65.

20. Wild S, Roglic G, Green A, Sicree R, King H. Global prevalence of diabetes: estimates for the year 2000 and projections for 2030. Diabetes Care. 2004;27:1047-53.

21. Shaw JE, Sicree RA, Zimmet PZ. Global estimates of the prevalence of diabetes for 2010 and 2030. Diabetes Res Clin Pract. 2010;87:4-14.

22. Scanlon PH, Aldington SJ, Stratton IM. Epidemiological issues in diabetic retinopathy. Middle East Afr J Ophthalmol. 2013; 20:293-300.

23. Amos AF, McCarty DJ, Zimmet P. The rising global burden of diabetes and its complications: estimates and projections to the year 2010. Diabet Med: a J Br Diabet Assoc. 1997;14(Suppl 5): S1-85.

24. King H, Aubert RE, Herman WH. Global burden of diabetes, 1995-2025: prevalence, numerical estimates, and projections. Diabetes Care. 1998;21:1414-31.

25. Minassian DC, Owens DR, Reidy A. Prevalence of diabetic macular oedema and related health and social care resource use in England. Br J Ophthalmol. 2012;96:345-9.

26. Gonzalez EL, Johansson S, Wallander MA, Rodriguez LA. Trends in the prevalence and incidence of diabetes in the UK: 1996-2005. J Epidemiol Community Health. 2009; 63:332-6.

27. Huang ES, Basu A, O'Grady M, Capretta JC. Projecting the future diabetes population size and related costs for the U.S. Diabetes Care. 2009;32:2225-9.

28. Waldeyer R, Brinks R, Rathmann W, Giani G, Icks A. Projection of the burden of type 2 diabetes mellitus in Germany: a demographic modelling approach to estimate the direct medical excess costs from 2010 to 2040. Diabet Med: a J Br Diabet Assoc. 2013;30:999-1008.

29. Foot B, MacEwen C. Surveillance of sight loss due to delay in ophthalmic treatment or review: frequency, cause and outcome. Eye. 2017;31:771-5.

30. The National Patient Safety Agency (NPSA). Preventing delay to follow up for patients with glaucoma. NPSA/2009/RRR004, June 2009. 